\title{
Covid-19 In Pregnant Women
}

\author{
Drashti Patel, Rakesh Kumar Jha and Praful Patil \\ ${ }^{1}$ First year MBBS student at Datta Meghe Medical College, Nagpur, India \\ ${ }^{2}$ Dept. of Biochemistry Datta Meghe Medical College, Shalinitai Meghe Hospital \\ and Research Centre Nagpur \\ ${ }^{3}$ Dept. of Microbiology Jawaharlal Nehru Medical College, Datta Meghe Institute \\ of Medical Sciences Sawangi (Meghe), Wardha \\ Corresponding author email: jhaarakesh1993@gmail.com
}

\section{ABSTRACT}

The outspread of Covid-19 also called as the novel Coronavirus started in 2019 in Wuhan, Hubei Province in China. From China it spread to the whole world at a very rapid rate. The common symptoms of this virus which is similar to SARS-CoV are infections in respiratory tract, acute respiratory distress syndrome, restlessness, body pain, loss of taste and smell, conjunctivitis and also pneumonia in severe cases which may or may not be life threatening. Since it affects in all age groups, pregnant women are also susceptible to this virus. However, in pregnant women with COVID-19 there is no evidence for vertical transmission but surely there is an increased risk of preterm deliveries by altering the immune response of the mother and the baby both as pregnant women are generally at risk of respiratory infections. Status of Covid-19 in Pregnant Women We concluded that pregnancy and child birth do not increase the pace of symptoms of this disease inside the body. It also does not aggravate the course of COVID-19 pneumonia. Even the women who do not get antiviral drugs treatment stay well off after child birth is over and achieve good recovery from COVID-19 pneumonia. Although negligence should be avoided while handling these type of cases as it might be life threatening.

KEY WORDS: COVID-19, PREGNANT WOMEN, PNEUMONIA, PRETERM DELIVERIES, NASOPHARYNGEAL SWAB AND VAGINAL DELIVERY.

\section{INTRODUCTION}

Coronavirus is a very recent virus which has changed the global scenario. (Jha et al., 2020) It is transmitted by the nasal droplets of the infected person when the person coughs, sneezes or talks. The incubation period of this virus is 2-14 days. It is there for the past 2 years and still there is no sign of reduced corona cases in any part of the world. The only way to stop its spread is by

Biosc Biotech Res Comm P-ISSN: 0974-6455 E-ISSN: 2321-4007

\section{crossef}

Identifiers and Pagination

Year: 2021 Vol: 14 No (6) Special Issue

Pages: 275-279

This is an open access article under Creative

DOI: $h t t p: / / d x$.doi.org/10.21786/bbrc/14.6.58
Commons License Attribn 4.0 Intl (CC-BY). isolating the person infected with all others he or she has come in contact with in past 14 days.

Also, the isolation period is of 14 days. It takes 5-6 days to show symptoms after the virus infects the body, it can take up to 14 days also. Boosting immunity,washing hands regularly with an alcohol-based rub and avoiding touching your mouth, nose and eyes is the only way to protect yourself from this virus and to slow down its transmission. It can be prevented by staying at home also. (Nazir et al., 2021 )People with mild symptoms are treated at their homes itself unless they show major symptoms and a great decrease in their oxygen levels. Some may also go asymptomatic yet may carry the capacity to spread the virus.
Article Information

Received: $29^{\text {th }}$ March 2021

ccepted after revision: $30^{\text {th }}$ May 2021 
When a woman is pregnant, she usually undergoes a great degree of changes in her body which brings along a lot of problems like urinary tract infections, mental health conditions, hypertension, obesity, anemia, various infections etc. All together we can say that the immunity of the mother is lowered down. (Favre et al., 2020) This increases a risk of respiratory infections and make the lungs and other respiratory organs weak. Also, anemia is a very common problem during pregnancy which causes decrease in red blood cells (RBC), which further results in decreased amount of oxygen transported to the tissues of the body.

What coronavirus (covid-19) does is it infects whole of the respiratory tract including lungs, nose, mouth etc. It lowers down the diffusion capacity of oxygen in lungs and therefore the tissues don't get enough of the oxygen to function. (Gungor et al., 2020) It also causes pneumonia which is the infections in lungs. As stated earlier pregnant women already undergo low levels of oxygen and if infected with covid it might further decrease. (Christiansen et al., 2013)This might be a threat but it has been noticed that covid-19 in pregnant women is not that big threat and there are chances but very less that the virus passes to the baby.

\section{DISCUSSION}

The risk of the infection of COVID-19 among the pregnant women and risk of vertical transmission has become a major concern. However various studies and researches state that there are very less chances of vertical transmission but still this is an issue being discussed all over the world. (Spoorthy et al., 2020) To study this, samples of amniotic fluid, breastmilk, etc are taken.

As stated by World Health Organisation (WHO), delay in clamping of umbilical cord reduces the risk of transmission of the virus even when the mother is infected. (Kliewer et al., 2005)It is also recommended to leave the vernix caseosa (a white coating on the skin of the new born that occurs during the last trimester for extra-uterine adaption of the skin) untouched for one whole day after the baby is born as it contains antimicrobial peptides. What concerns more is transmission after birth through various means from mother to the baby and for this separation of the child from mother is considered. (Qiao et al., 2020).

Breastfeeding while infected with COVID-19 cannot be avoided but it should be done with utmost care and precautions and should be carried out by wearing a mask and washing hands before touching the infant. (Mei et al., 2020) According to a study and review by the Frontiersin, the most common symptoms of COVID-19 in pregnant women are fever, cough, myalgia (pain in muscles) and also dyspnea (shortness of breath). CT scans, nasopharynx swab etc also showed positive reports for coronavirus or COVID-19.

If the disease reaches a greater level inside the body of the mother, then termination of pregnancy is suggested which would be safe for the mother as well as for the baby. (Ferdous et al., 2020) Cesarean section should be preferred over normal vaginal delivery to solve this purpose. (Huanhuan et al., 2020) Even in case the baby is being delivered from an infected mother, C-sections was reported and no vaginal deliveries were reported in a study conducted by the Cambridge University press. Drugs like interferon-alpha, lopinavir and chloroquine can be given to the patients rather than remdesivir and arbidol as they are not yet proven to be safe at the time of pregnancy but when not pregnant, they are 100\% accurate. (Somashekhar et al., 2020) Antibiotics and corticosteroids are also recommended to the infected pregnant women.

Testing of COVID-19 was done by using nasopharyngeal swab and by PCR (chain polymerase reaction) in total 156 pregnant women. Out of these eight one tested positive. From the positive one's total sixty women had undergone the test because they had symptoms and twenty-one took the test because they were exposed to the coronavirus. In total, forty-six women were symptomatic and twenty-two were asymptomatic. From the women who showed the symptoms $27.3 \%$ had preterm delivery and respiratory support was also needed by $26.1 \%$ of them. (Luo et al., 2020) On the other hand, no women from the asymptomatic group neither had preterm deliveries nor did they require respiratory support.

(Kliewer et al., 2005) In another case study from the AMERICAN JOURNAL OF ROENTGENOLOGY 15 patients were considered and their clinical data and CT examination was done. The lab results and clinical outcomes that were tracked are as follows. (Wanjari et al., 2020) Eleven out of fifteen patients had normal successful deliveries from which 10 of them were cesarean and 1 was vaginal delivery. The other 4 were still pregnant at that time. Neonatal asphyxia, neonatal death, stillbirth was not reported in any of the cases by the time the study was completed.

The most common symptoms shown in the infected pregnant women were pneumonia, fever in 13 of them and cough in 9 of them. (Dhankasar et al., 2020) Abnormal laboratory finding that was common among them was lymphocytopenia i.e., in 12 out of 15 patients. No sign of pneumonia aggravation was seen in the CT scans before and after the child birth. (Kunz et al., 2020) The women that were pregnant initially also had normal deliveries and recovered soon. 


\section{CONCLUSION}

From this review article we can conclude that pregnant women infected with COVID-19 who are symptomatic have higher rate of preterm deliveries and pneumonia infections leading to the requirement of respiratory support whereas asymptomatic pregnant women might not require these. It is of chief importance to take utmost care of the symptomatic and COVID-19 positive women.

We can also conclude that pregnancy and child birth do not increase the pace of symptoms of this disease inside the body. It also does not aggravate the course of COVID19 pneumonia. Even the women who do not get antiviral drugs treatment stay well off after child birth is over and achieve good recovery from COVID-19 pneumonia. Although negligence should be avoided while handling these type of cases as it might be life threatening.

\section{REFERENCES}

Christiansen, O.B., 2013. Reproductive immunology. Molecular immunology, 55(1), pp.8-15.

Dhankasar, P., Dhole, P., Kolhe, S., Dambare, M., Rewatkar, P. and Balpande, V., 2020. The Unseen Positive Effect of Covid-19 Pandemic. Journal of Research in Medical and Dental Science, pp.108-112. Favre, G., Pomar, L., Musso, D. and Baud, D., 2020. 2019-nCoV epidemic: what about pregnancies?. Lancet (London, England), 395(10224), p.e40.

Ferdous, M.Z., Islam, M.S., Sikder, M.T., Mosaddek, A.S.M., Zegarra-Valdivia, J.A. and Gozal, D., 2020. Knowledge, attitude, and practice regarding COVID19 outbreak in Bangladesh: An online-based crosssectional study. PloS one, 15(10), p.e0239254.

Gungor, B., Atici, A., Baycan, O.F., Alici, G., Ozturk, F., Tugrul, S., Asoglu, R., Cevik, E., Sahin, I. and Barman, H.A., 2020. Elevated D-dimer levels on admission are associated with severity and increased risk of mortality in COVID-19: A systematic review and meta-analysis. The American journal of emergency medicine.

Huanhuan, L., Fang, L., Jinning, L., Tingting, Z., Dengbin, W. and Weishun, L., 2020. Clinical and CT imaging features of the COVID-19 pneumonia: Focus on pregnant women and children. https://www. ncbi. nlm. nih. gov/pmc/articles/PMC7156118/pdf/main. pdf.
Jha, R.K., Jain, P. and Ambad, R.S., 2020. The origin, transmission and mortality of corona virus. Journal of critical reviews, 7(10), pp.93-96.

Kliewer, M.A., Freed, K.S., DeLong, D.M., Pickhardt, P.J. and Provenzale, J.M., 2005. Reviewing the reviewers: comparison of review quality and reviewer characteristics at the American Journal of Roentgenology. American Journal of Roentgenology, 184(6), pp.1731-1735.

Kunz, R. and Minder, M., 2020. COVID-19 pandemic: palliative care for elderly and frail patients at home and in residential and nursing homes. Swiss medical weekly, 150(1314).

Latchoumi, T.P., Ezhilarasi, T.P. and Balamurugan, K., 2019. Bio-inspired weighed quantum particle swarm optimization and smooth support vector machine ensembles for identification of abnormalities in medical data. SN Applied Sciences, 1(10), pp.1-10.

Luo, Y. and Yin, K., 2020. Management of pregnant women infected with COVID-19. The Lancet Infectious Diseases, 20(5), pp.513-514.

Mei, Y., Luo, D., Wei, S., Liao, X., Pan, Y., Yang, X. and Lin, Y., 2020. Obstetric management of COVID19 in pregnant women. Frontiers in microbiology, 11, p. 1186.

Nazir, R., Ali, J., Rasul, I., Widemann, E. and Shafiq, S., 2021. Eco-Environmental Aspects of COVID-19 Pandemic and Potential Control Strategies. International Journal of Environmental Research and Public Health, 18(7), p.3488.

Qiao, J., 2020. What are the risks of COVID-19 infection in pregnant women?. The Lancet, 395(10226), pp.760762.

Somashekhar, S.P., Shivaram, H.V., Abhaham, S.J., Dalvi, A., Kumar, A., Gode, D., Misra, S., Jain, S.K., Prasad, C.R.K. and Pillarisetti, R.R., 2020. ASI's consensus guidelines: $\mathrm{ABCs}$ of what to do and what not during the COVID-19 pandemic.

Spoorthy, M.S., Pratapa, S.K. and Mahant, S., 2020. Mental health problems faced by healthcare workers due to the COVID-19 pandemic-A review. Asian journal of psychiatry, 51, p.102119.

Wanjari, A.K., Dubey, A., Chaturvedi, S. and Kumar, S., 2020. Young COVID 19 presenting as fatal subarachnoid hemorrhage: Association or chance. Medical Science, 24(104), pp.2712-2715. 